\title{
Surface-Activated Corrosion in Tin-Lead Halide Perovskite Solar Cells
}

Laura E. Mundt*1, Jinhui Tong', Axel F. Palmstrom², Sean P. Dunfield ${ }^{2,3}$, Kai Zhu' ${ }^{2}$, Joseph J. Berry $^{2}$, Laura T. Schelhas ${ }^{1,2}$, Erin L. Ratcliff*, ${ }^{*, 5,6}$

${ }^{1}$ SLAC National Accelerator Laboratory, 2575 Sand Hill Rd, Menlo Park, CA 94025

${ }^{2}$ National Renewable Energy Laboratory, 15013 Denver W Pkwy, Golden, CO 80401

${ }^{3}$ Materials Science and Engineering Program, University of Colorado Boulder, 027 UCB, Suite N321, Boulder, CO 80303, USA

${ }^{4}$ Department of Materials Science and Engineering, University of Arizona, 1235 E. James E. Rogers Way, Tucson, AZ 85721

${ }^{4}$ Department of Chemical and Environmental Engineering, University of Arizona, 1133 E. James E. Rogers Way, Tucson, AZ 85721

${ }^{6}$ Department of Chemistry and Biochemistry, University of Arizona, 1306 E. University Blvd., Tucson, AZ 85721

\section{Corresponding Author}

*Laura E. Mundt (1mundt@slac.stanford.edu), Erin L. Ratcliff ( $\underline{\text { ratcliff@email.arizona.edu })}$ 


\section{EXPERIMENTAL METHODS}

\section{LOW-BANDGAP PEROVSKITE SOLAR CELLS}

Devices and thin films were prepared following previously reported procedures. ${ }^{1}$ For the perovskite precursor, formamidinium iodide $\left(\mathrm{CH}_{5} \mathrm{IN}_{2}\right)(0.6 \mathrm{mmol})$, methyl ammonium iodide $\left(\mathrm{CH}_{3} \mathrm{NH}_{3} \mathrm{I}\right)(0.4 \mathrm{mmol}), \mathrm{SnF}_{2}(0.6 \mathrm{mmol}), \mathrm{SnI}_{2}(0.6 \mathrm{mmol})$ and $\mathrm{PbI}_{2}(0.4 \mathrm{mmol})$ was dissolved in a solution consisting of $800 \mu \mathrm{l}$ of dimethyl formamide (DMF) and $200 \mu \mathrm{l}$ dimethyl sulfoxide (DMSO) solution. Films were made by spin coating, using toluene as an antisolvent and thermally aged at $100^{\circ} \mathrm{C}$ for 10 minutes. The devices were in $\mathrm{p}$-i-n architecture, as depicted in Figure $1 \mathrm{~b}$, with a spin-cast layer of PEDOT:PSS as hole transport layer (HTL) on pre-patterned indium tin oxide (ITO) glass substrate. The electron transport layer (ETL) was comprised of $30 \mathrm{~nm} \mathrm{C}_{60}, 6 \mathrm{~nm}$ bathocuproine (BCP) and $100 \mathrm{~nm} \mathrm{Ag}$, both layers were sequentially deposited by thermal evaporation on top of the absorber layer. The absorber composition was $\left(\mathrm{HC}\left(\mathrm{NH}_{2}\right)_{2}\right)_{0.6}\left(\mathrm{CH}_{3} \mathrm{NH}_{3}\right)_{0.4} \mathrm{Sn}_{0.6} \mathrm{~Pb}_{0.4} \mathrm{I}_{3}$.

\section{DEVICE STABILITY}

Solar cells without any encapsulation were loaded into a custom degradation testing setup, dubbed the Stability Parameter Analyzer (SPA). The setup consists of a flow chamber to control the environment of the cells, electrical housing and electronics that switch between devices, measure JV curves, and hold the devices under resistive load, and a light source that provides constant illumination. In this study, devices were kept in a $\mathrm{N}_{2}$ environment illuminated by a sulfur plasma lamp at $\sim 0.7$ Suns and held under a resistive load of 510 Ohms (placing the cells near maximum power point). The samples were heated to approximately $23{ }^{\circ} \mathrm{C}$. Approximately every 
30 minutes, the system removes the resistive load and takes a JV scan using a Keithley 2450 source-measure unit. JV curves are then analyzed to extract relevant parameters.

\section{OPERANDO X-RAY DIFFRACTION}

The scattering experiments were conducted at the Stanford Synchrotron Radiation Lightsource (SSRL) at beamline 2-1. The technique was previously described in ${ }^{2}$ and ${ }^{3}$. The incident X-ray energy was $12.5 \mathrm{keV}$ and the devices were probed at an incident angle of $3^{\circ}$ and a flux of approximately $4.9 \cdot 10^{10}$ photon $\mathrm{s}^{-1} \mathrm{~mm}^{-2}$. The sample was aligned to allow the incident beam to hit the top electrode (Ag pad, see Figure S1). Scattered X-rays were detected using the Pilatus 100K small area detector. The measurements were conducted in a flat plate geometry and $\mathrm{LaB}_{6}$ was used as calibration standard. The sample chamber was sealed with X-ray transparent Kapton tape and flowed with either $\mathrm{He}$ or $\mathrm{N}_{2}$ gas for the measurements in inert conditions. For the measurements in ambient conditions, part of the Kapton tape was removed the samples were exposed to ambient air with $\mathrm{RH}$ of $65 \%$. Elevated temperatures were reached by heating the cap of the sample chamber. A thermocouple (TC) was placed next to the sample to monitor the temperature. Prior to the measurements, a dummy sample (identical thickness / layer stack) was equipped with the TC directly on top of the sample and the actual sample temperature for different settings was recorded to determine the temperature offset between the sample and the TC readout when placed next to the sample. Spectrally matched, approximately 1 sun equivalent illumination was provided by the Asahi Spectra Hal-320 Solar Simulator. A full measurement cycle included two current-voltage scans (forward and reverse) and a consequent XRD scan (scan time: $30 \mathrm{~s}$ ) during which the device was held at maximum power conditions. This sequence was repeated every 15 minutes with the device being hold at the maximum power point in between. The operando experiments were 
performed both in inert and ambient (air and 65\% RH) conditions at three different temperatures: $40^{\circ} \mathrm{C}, 60^{\circ} \mathrm{C}$ and $80^{\circ} \mathrm{C}$.

\section{X-RAY PHOTOELECTRON SPECTROSCOPY}

XPS measurements were performed with a Kratos Axis Ultra X-ray photoelectron spectrometer with a monochromatic $\mathrm{Al} \mathrm{K} \alpha$ source $(1486.6 \mathrm{eV})$ at a base pressure of $10^{-9}$ Torr. Photoelectrons were collected in a hemispherical analyzer and detected with a photodiode array. A $20 \mathrm{eV}$ pass energy was used for all element specific spectral acquisitions. Resulting XPS spectra were first baseline corrected and then fit using a 70\% Gaussian, 30\% Lorentzian peak shape. Spectra were collected for as deposited films and after a thermal treatment at $60^{\circ} \mathrm{C}$ for $60 \mathrm{~min}$ in either an inert glove box $\left(<2 \mathrm{ppm} \mathrm{O}_{2}\right)$ or in ambient conditions (air and 20\% RH). Presented data are representative of multiple samples, validating reproducibility of results. 


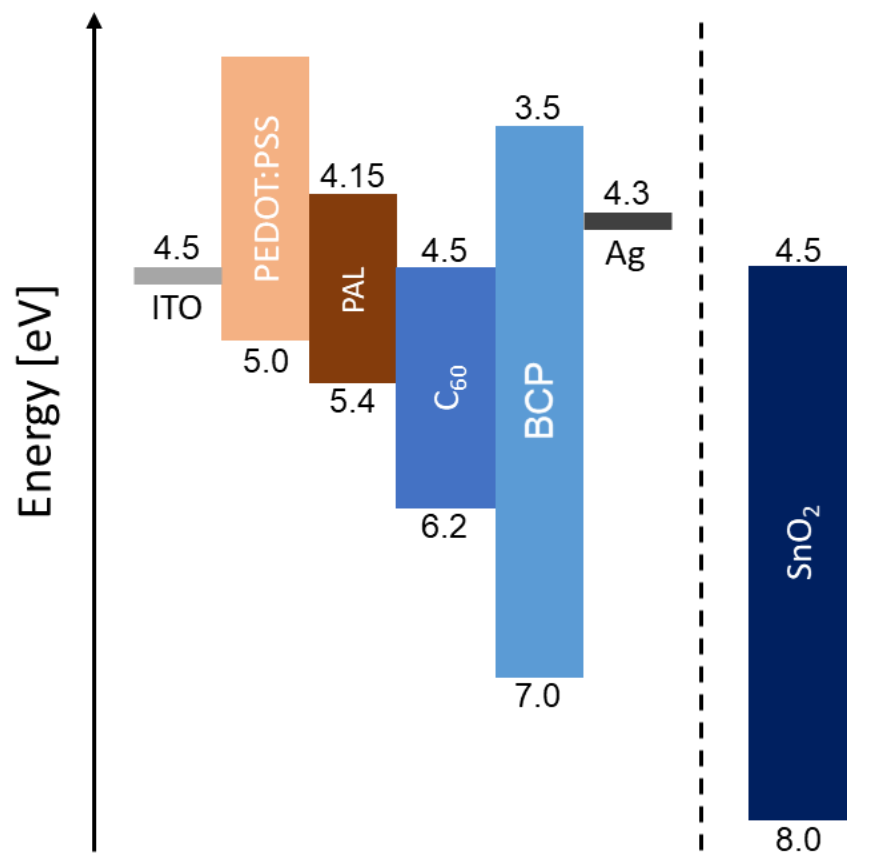

Figure S1. Schematic band diagram for the device layer stack with the perovskite active layer (PAL), additionally showing the energy band for $\mathrm{SnO}_{2}$.

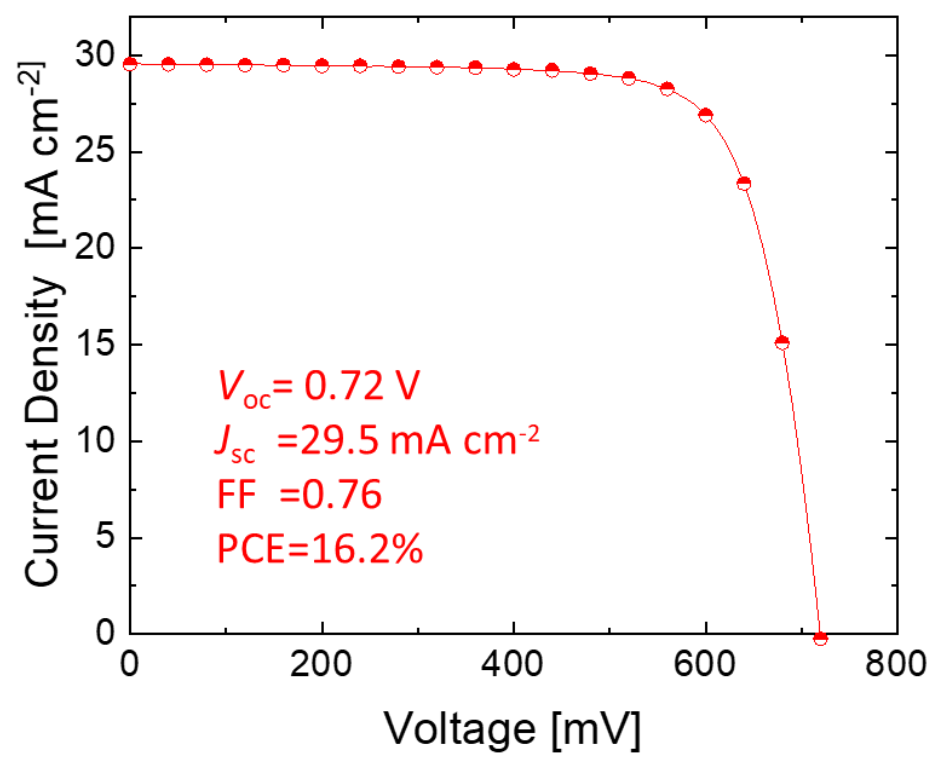

Figure S2. Typical JV curve for the mixed lead-tin devices before degradation. 


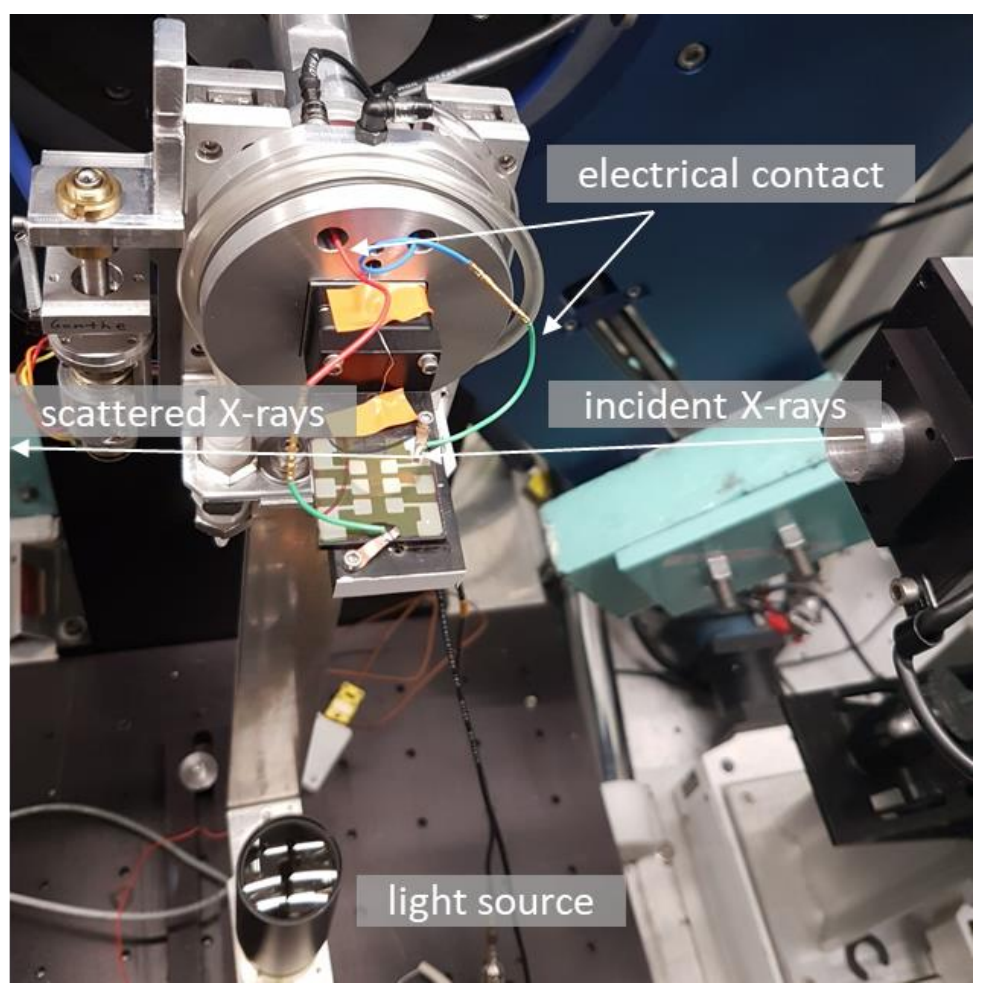

Figure S3. Experimental setup for operando X-ray diffraction experiment. Picture depicts sample stage with contacted perovskite device without the cap on the sample chamber. 

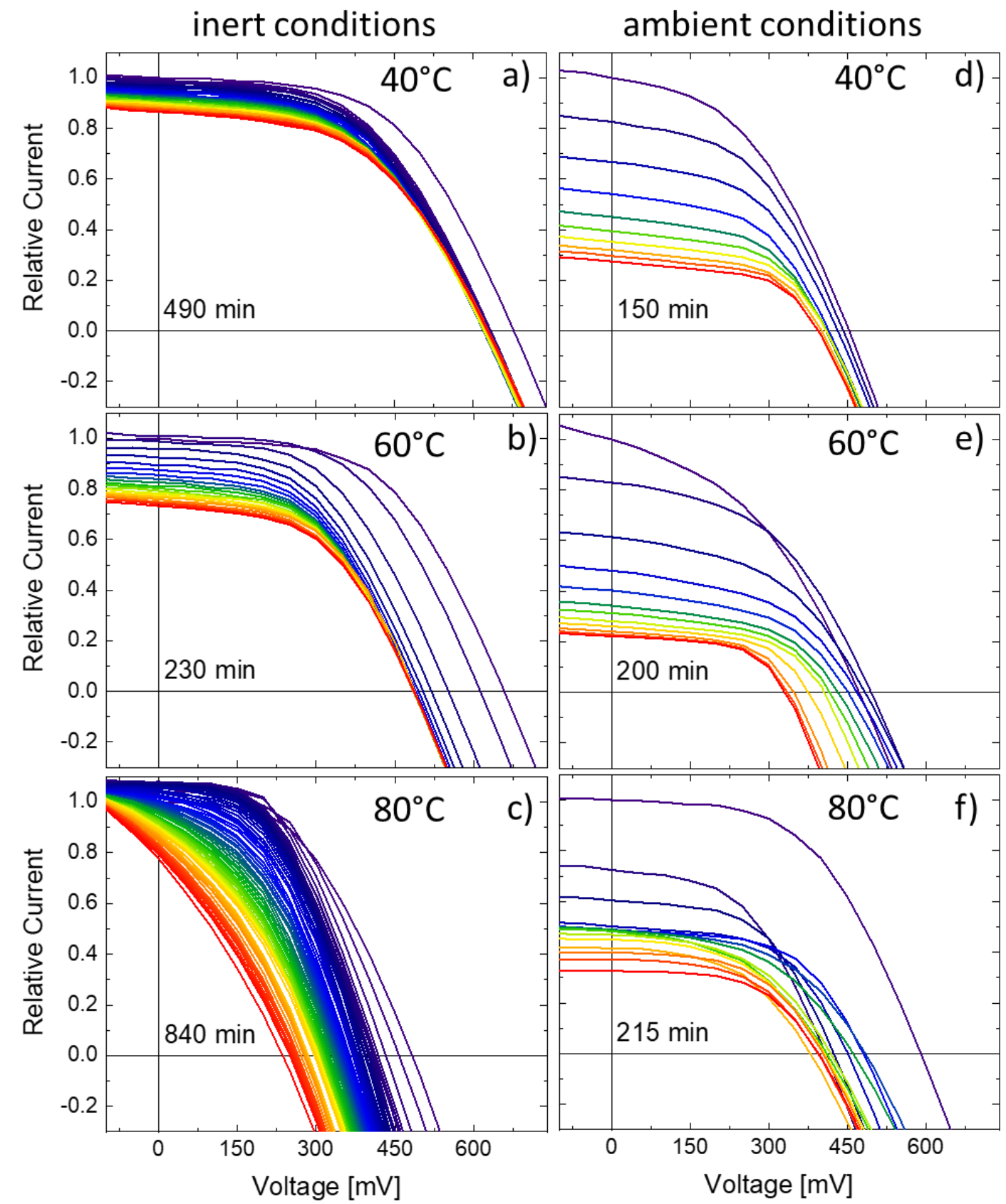

Figure S4. Reverse IV curves measured in the operando setup at the beamline, showing the relative current to simplify comparison and account for variations caused by the experimental setup (c.f. previous reports of the technique ${ }^{2}$ ). Left panel (a-c) shows the results in inert conditions, right panel (d-f) the results in ambient (air, 65\% RH) conditions. Temperatures are indicated in the individual plots, increasing from first row to third row. 


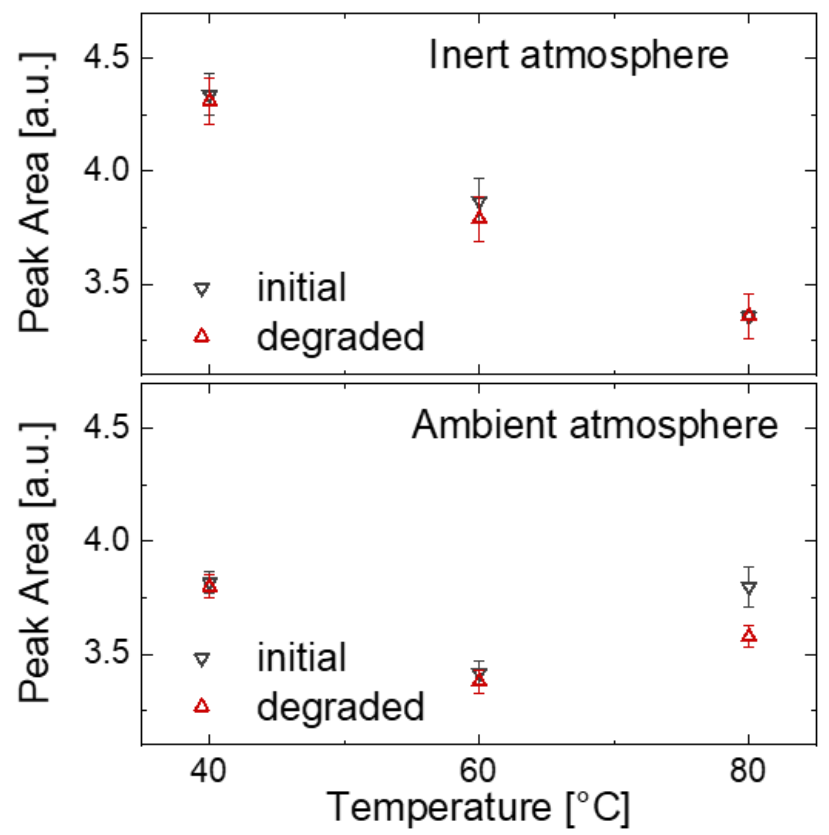

Figure S5. Comparison of perovskite (100) peak intensity before and after degradation in inert (top box) and ambient (bottom box) conditions. Peak fitting used a Voigt function and a linear background. 

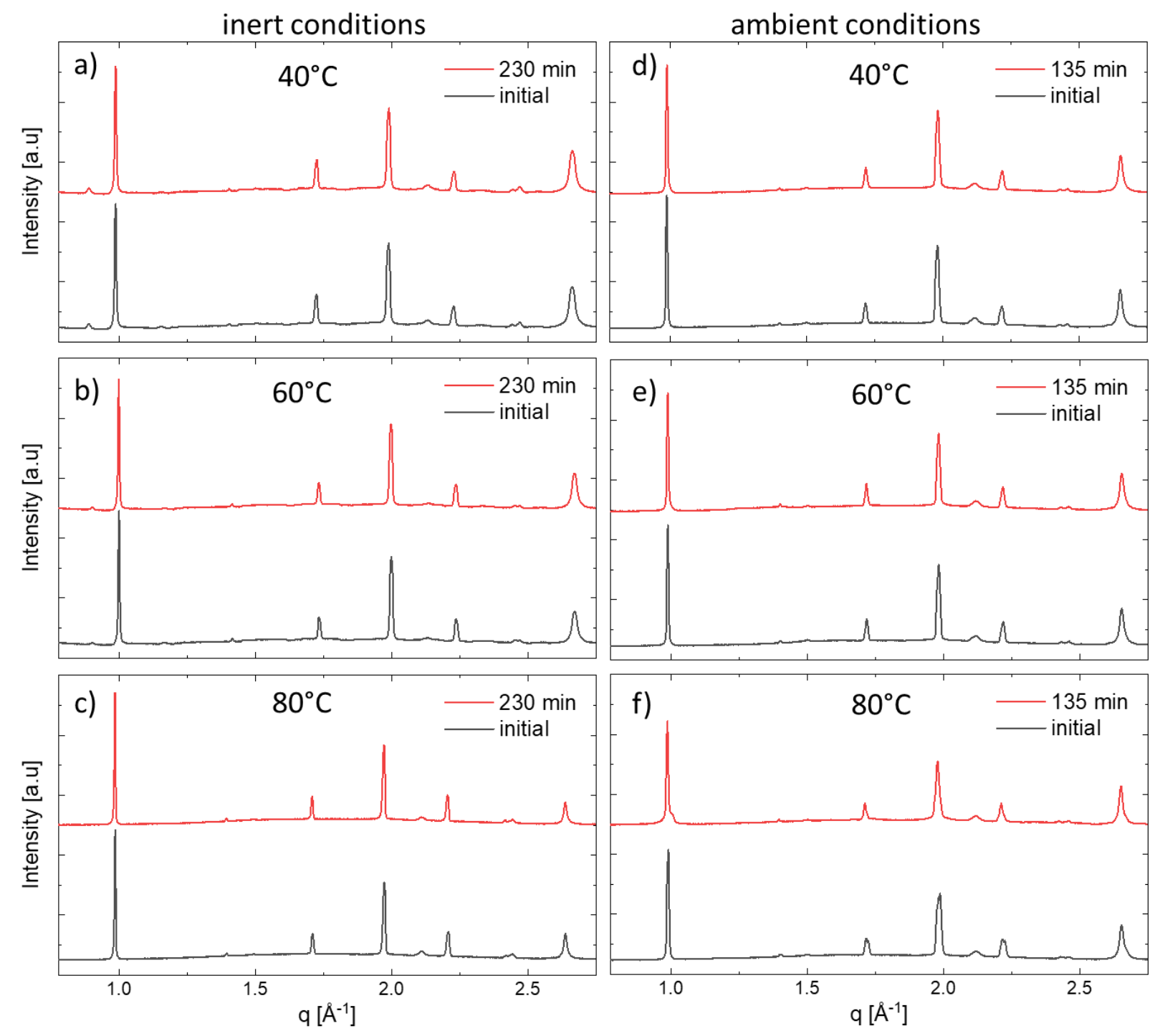

Figure S6. Diffraction data comparing initial and degraded state for operando experiment at $40^{\circ} \mathrm{C}$, $60^{\circ} \mathrm{C}$ and $80^{\circ} \mathrm{C}$ in inert and ambient atmosphere. The degraded state (red line) refers to the measurement after $230 \mathrm{~min}$ for inert conditions (a-c) and after $135 \mathrm{~min}$ for ambient conditions (df), taking into account the accelerated degradation in ambient conditions. 

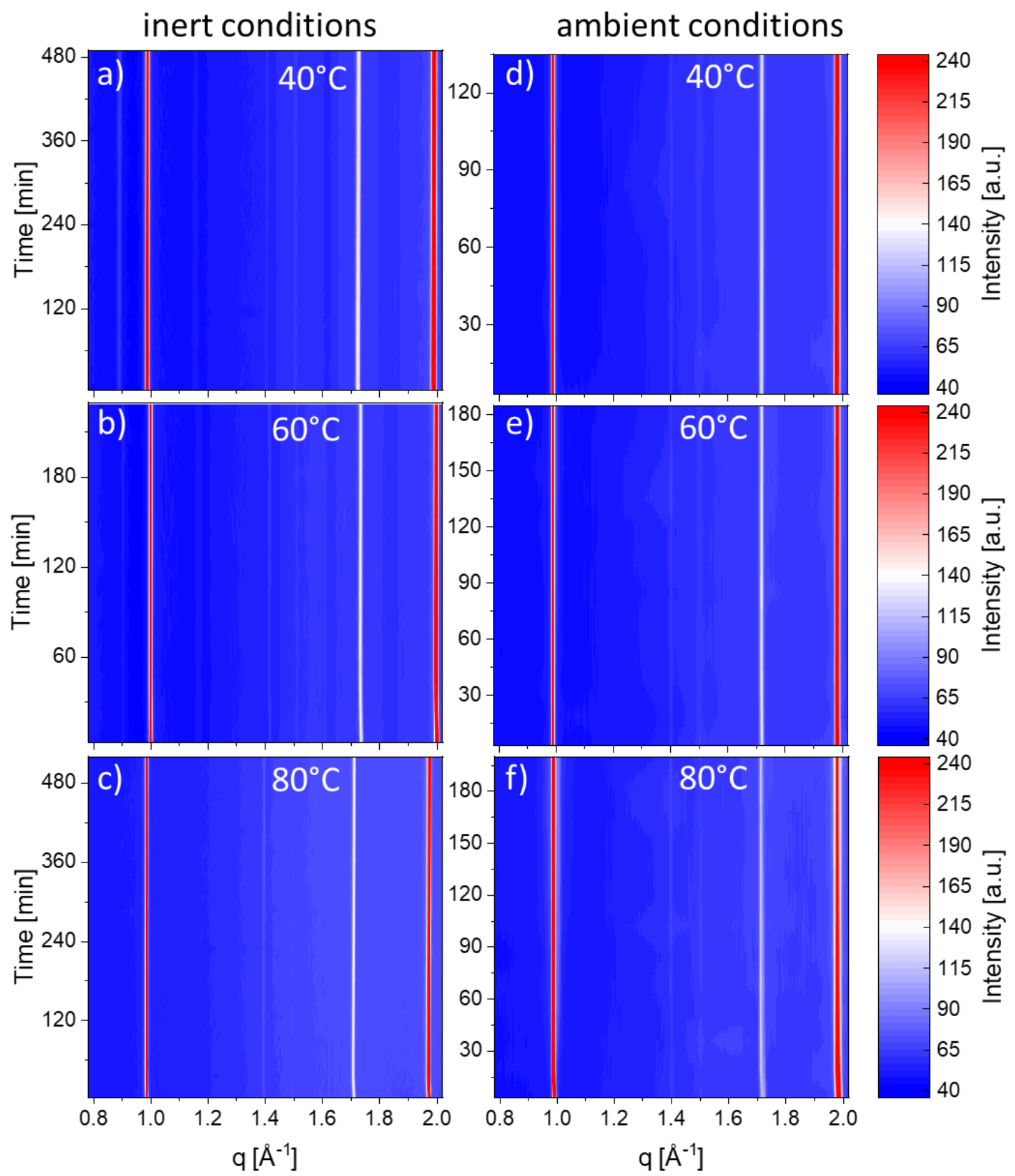

Figure S7. Waterfall plots to show diffraction patterns over time for $40^{\circ} \mathrm{C}, 60^{\circ} \mathrm{C}$ and $80^{\circ} \mathrm{C}$ in inert (a-c) and ambient (d-f) conditions. Note that the time scales are different for the individual samples. 


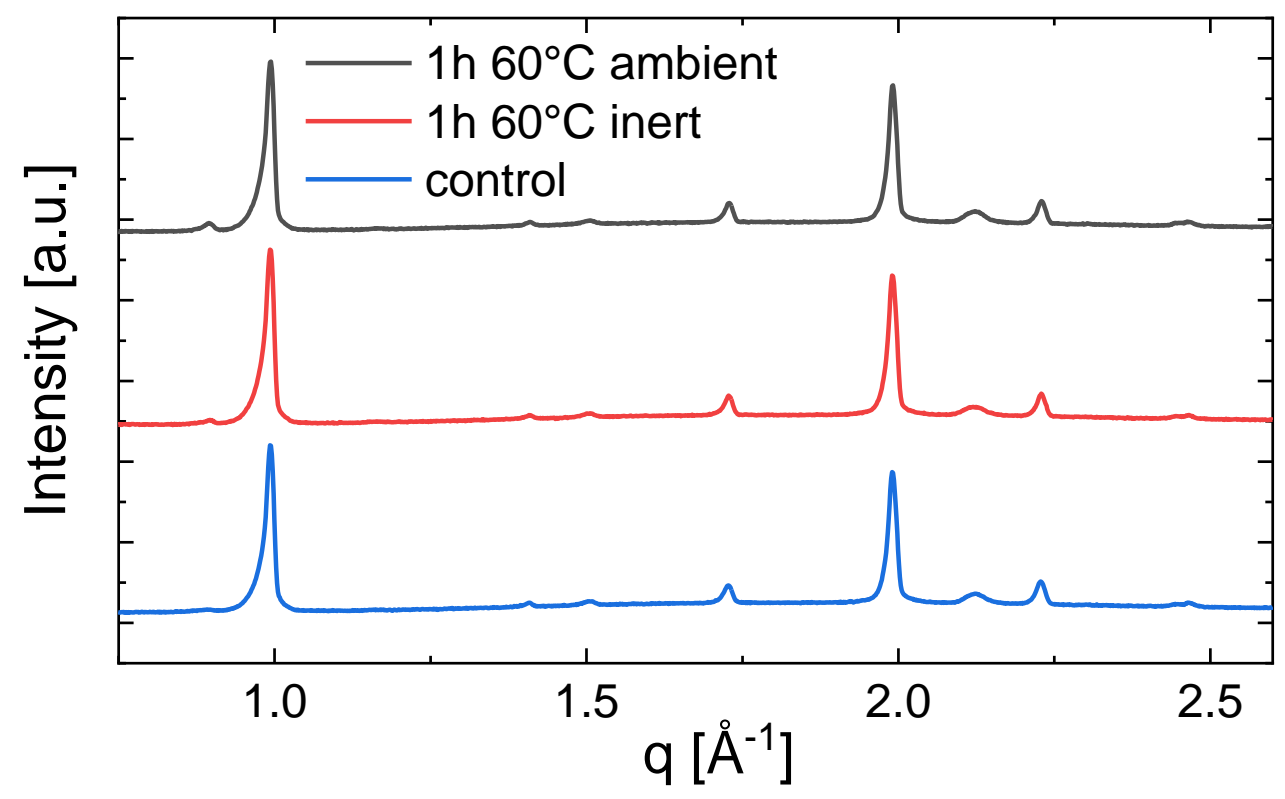

Figure S8. Additional $\mathrm{XRD}$ data from $\left(\mathrm{HC}\left(\mathrm{NH}_{2}\right)_{2}\right)_{0.6}\left(\mathrm{CH}_{3} \mathrm{NH}_{3}\right)_{0.4} \mathrm{Sn}_{0.6} \mathrm{~Pb}_{0.4} \mathrm{I}_{3}$ thin films on glass/ITO/PEDOT:PSS substrates. The films were measured as received (blue, "control”), after aging for 1 hour under $\mathrm{N}_{2}$ at $60^{\circ} \mathrm{C}$ (red, " $1 \mathrm{~h} 60^{\circ} \mathrm{C}$ inert) and after aging for 1 hour in ambient conditions (air and $\sim 55 \% \mathrm{RH}$ ) (dark grey, " $1 \mathrm{~h} 60^{\circ} \mathrm{C}$ ambient). 


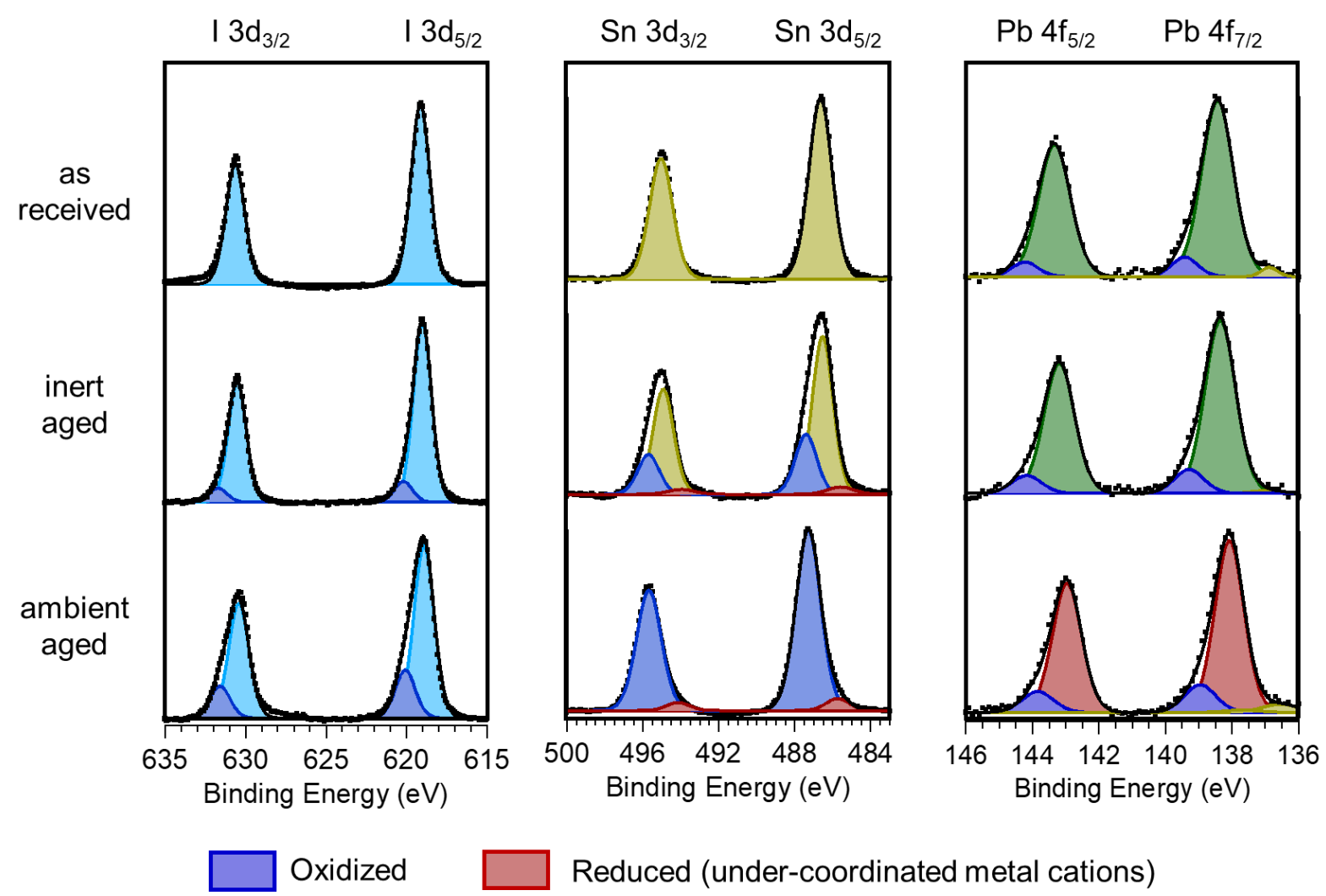

Figure S9. Additional XPS data showing complete doublets and corresponding chemical fits for I 3d, $\mathrm{Sn} 3 \mathrm{~d}$ and $\mathrm{Pb} 4 \mathrm{f}$. Peaks corresponding to perovskite environments are highlighted in green for $\mathrm{Pb} 4 \mathrm{f}$, yellow for $\mathrm{Sn} 3 \mathrm{~d}$ and light blue for I. Oxidized species are indicated by dark blue and the peaks related to the reduced, under-coordinated metal cations are shown in red. 


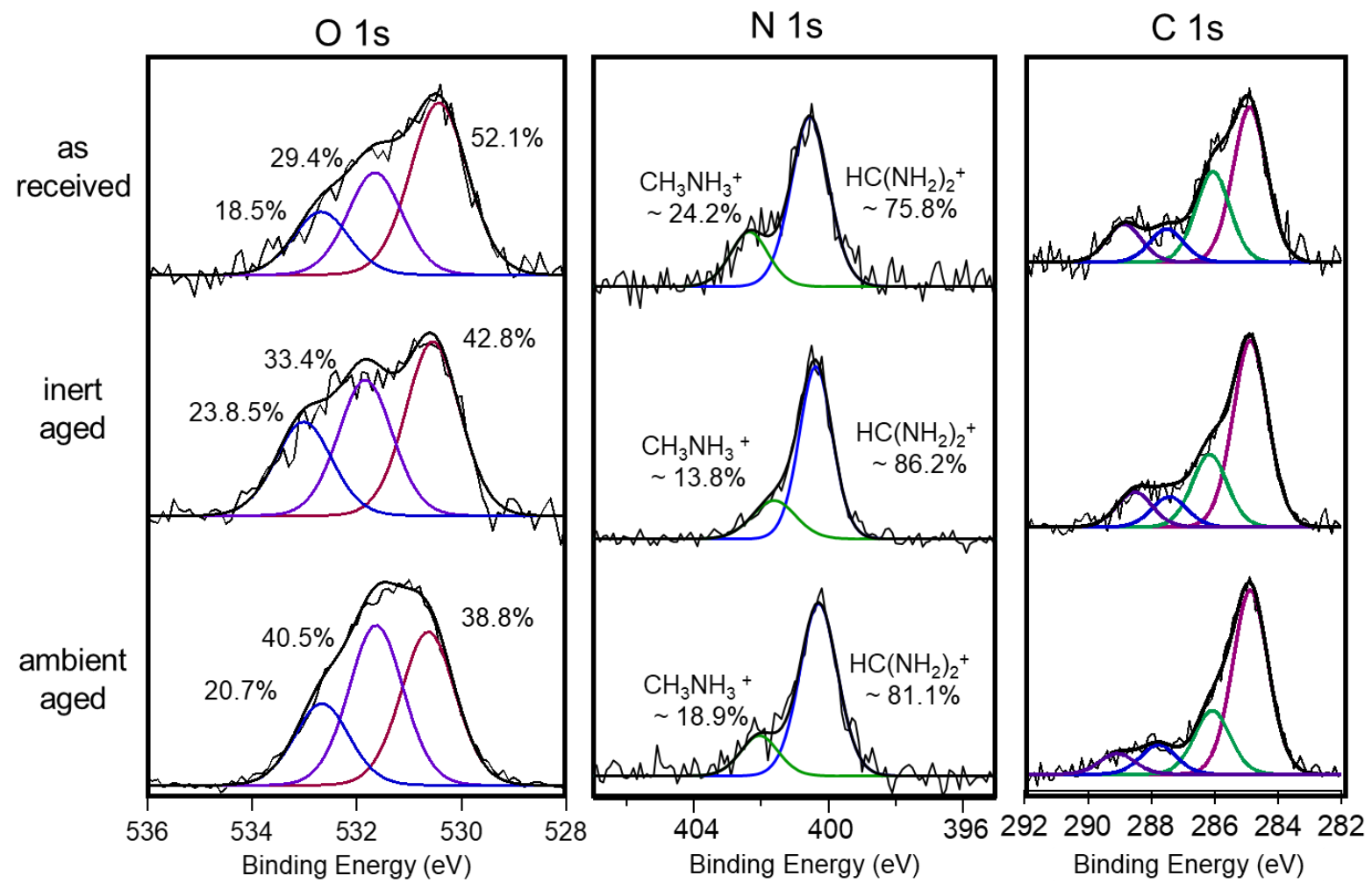

Figure S10. Additional XPS data showing core levels and corresponding chemical fits for O 1s, $\mathrm{N} 1 \mathrm{~s}$ and $\mathrm{C} 1 \mathrm{~s}$.

(1) Tong, J.; Song, Z.; Kim, D. H.; Chen, X.; Chen, C.; Palmstrom, A. F.; Ndione, P. F.; Reese, M. O.; Dunfield, S. P.; Reid, O. G.; Liu, J.; Zhang, F.; Harvey, S. P.; Li, Z.; Christensen, S. T.; Teeter, G.; Zhao, D.; Al-Jassim, M. M.; Van Hest, M. F. A. M.; Beard, M. C.; Shaheen, S. E.; Berry, J. J.; Yan, Y.; Zhu, K. Carrier Lifetimes of $>1$ Ms in Sn-Pb Perovskites Enable Efficient All-Perovskite Tandem Solar Cells. Science (80-. ). 2019, 364 (6439), 475-479. https://doi.org/10.1126/science.aav7911.

(2) Schelhas, L. T.; Christians, J. A.; Berry, J. J.; Toney, M. F.; Tassone, C. J.; Luther, J. M.; Stone, K. H. Monitoring a Silent Phase Transition in CH3NH3PbI3 Solar Cells via Operando X-Ray Diffraction. ACS Energy Lett. 2016, 1 (5), 1007-1012. 
https://doi.org/10.1021/acsenergylett.6b00441.

(3) Schelhas, L. T.; Li, Z.; Christians, J. A.; Goyal, A.; Kairys, P.; Harvey, S. P.; Kim, D. H.;

Stone, K. H.; Luther, J. M.; Zhu, K.; Stevanovic, V.; Berry, J. J. Insights into Operational Stability and Processing of Halide Perovskite Active Layers. Energy Environ. Sci. 2019, 12 (4), 1341-1348. https://doi.org/10.1039/c8ee03051k. 